\title{
Coast function parameters optimization for DC battery source inverter feeding three-phase inductive load
}

\author{
Riyadh G. Omar \\ Department of Electrical Engineering, College of Engineering, Mustansiriyah University, Iraq
}

\begin{tabular}{l} 
Article Info \\
\hline Article history: \\
Received Feb 28, 2020 \\
Revised Apr 26, 2020 \\
Accepted Jun 10, 2020 \\
\hline
\end{tabular}

Keywords:

Absolute error (AE)

Cost-function

Finite control set (FCS)

percentage error $(\mathrm{PE})$

Square error (SE)

\begin{abstract}
The commonly reported measures of the predictive accuracy are evaluated in this paper. Absolute, squared, percentage, and integral errors methods are implemented, to reduce the objective function, which employed in model predictive control. These methods are usually investigated for dc source inverter, which controlled by finite set model predictive current control system, with three-phase induction motor load. In this paper, the evaluation includes different aspects, accuracy, complexity, system harmonics content, and execution time. A vital criterion in this process is the performance of the inverter, and the matching between the reference and the measured machine currents. The evaluation shows that for one term objective function, absolute and square errors give similar results with less execution time for the absolute error, but if multi terms objective function the square error is better.
\end{abstract}

This is an open access article under the CC BY-SA license.

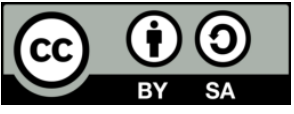

Corresponding Author:

Riyadh Ghanem Omar,

Department of Elecrical Engineering,

Mustansiriyah University, Baghdad, Iraq.

Email: dyala1968@gmail.com

\section{INTRODUCTION}

The first thought of Model Predictive Control (MPC) and Rretreating Horizon Control (REC) can be followed back to the 1960s when it was utilized as an intend to manage multivariable compelled control issues. The chemical and oil industrys, were pioneers in the appropriation of MPC, while the principal attempt to apply it to an electrical drive framework was made over two decades later [1-6]. Since for a two level voltage source inverter (VSI), there are eight mixes of inverter expresses, the wording of finite control set (FCS) is given. Moreover, the advancement of the inverter states is performed utilizing the retreating horizon control method, the center of model predictive control. The idea of MPC depends on the estimation of things to come conduct of the system, to use this data to find out ideal quantities for the inciting variables [7-10]. Execution of this method can be isolated into three principal steps: estimation of the factors that cannot be estimated, prediction of things to come conduct of the system, and system outputs optimization. Prescient control has many favorable circumstances that make it a genuine choice if high powerful control of electrical drives is required. The idea is straightforward and execute, also many system constraints can be added, multivariable cases can be considered, and nonlinearity can be incorporated [11]. This control strategy requires bunches of estimations contrasted with conventional methods. Despite that the prescient control plot depends on further developed control hypothesis, the subsequent control procedure is not any more mind-boggling than a traditional plan dependent on PI controllers and space vector modulation (SVM). Both control plans need a model of the inverter and the voltage vectors that it creates. In the old style plot, information on the voltage vectors is utilized for execution of the modulator. These voltage vectors are the limited arrangement (finite) of potential incitations in predictive control strategy. To alter the PI 
controllers, linear equations representing the load model is required. The controller in the new strategy will compute the voltage vector next predictions. This can be accomplished by using a discrete-time version of the load model. The presentation of the PI controllers relies upon the suitable change of their parameters kp and ki [12]. This can be avoided in the new control strategy since no parameter's adjustment is needed. A cost capacity must be characterized, which on account of current control is extremely basic.

Intrigue additionally has expanded in figuring out which mathematical method will produce increasingly exact and exact predictions of the variables under control [13,14]. Our motivation in this note is to investigate and decipher accessible factual proportions of the normal error related with a lot of modeldelivered predictions. In this work an examination of the overall capacities of 1- average model performance error, 2-the square error (SE), 3- the absolute percentage error (APE), and 4- the absolute error (AE). Every one of these measures represents the error value in model variables for each prediction. These measures additionally have been utilized to appear the difference between the estimates to find which one is the most reliable.

Figuring of $\mathrm{AE}$ is generally basic. It includes adding the amounts of the absolute errors to get the total error value. Computing the SE is achieved by summing each square error. Every error value impacts the aggregate in relation to its square, instead of its amount. Enormous mistakes, as a result, affect the aggregate square error than do the littler errors. This implies that the complete square error will develop as the over all error is thought inside a diminishing number of progressively huge individual errors. The absolute percentage error (APE) is one of the most broadly utilized proportions of conjecture precision, because of its points of interest of scale-independency and interoperability. In addition, the integral for the absolute error (IAE) can be applied to compute the cost function, this function represents the system necessities by adding many small parts including with it. These parts are controlled variables reference following part that can be motor torque, speed or load current and voltage. As an example, for one variable the various methods of cost function (G) evaluation are:

$$
G=\left|y_{\text {reference }}(k+1)-y_{\text {predicted }}(k+1)\right|
$$

Where, $\mathrm{y}_{\text {reference }}$ is the reference variable will not to be controlled while, $\mathrm{y}_{\text {predicted }}$ is the predicted value for the same variable. The two parts are calculated at the instant of $(k+1)$ after discretizing the system model. The MSE and IAE are shown in equations (2) and (4).

$$
\begin{aligned}
& G=\left(y_{\text {reference }}(k+1)-y_{\text {predicted }}(k+1)\right)^{2} \\
& G=\left|y_{\text {reference }}(k+1)-y_{\text {predicted }}(k+1)\right| /\left|y_{\text {predicted }}(k+1)\right| \\
& G=\int_{0}^{T_{S}}\left|y_{\text {reference }}(t)-y_{\text {predicted }}(t)\right| d t
\end{aligned}
$$

Comparing equations 1 and 2, the last one produces large cost function for error values more than (1) while give a small results for errors less than (1). In power electronics, the first one will affect on the behavior of the controller sensitivity and much faster one is needed with high switching frequencies. While the second will reduce the sensitivity for small changes but with less reference tracking possibilities. For the (APE) as in equation (3) the huge detriment that it produces interminable or unclear qualities for zero or near zero values.

\section{GENERAL DESCRIPTION OF DC BATTERY SOURCE INVERTER WITH THREE-PHASE INDUCTIVE LOAD}

The standard form of the DC battery source inverter is exhibited in Figure 1 [15-25], which is familiar power electronics hardware utilized for driving three-phase inductive load. This device employs six IGBT switches $\left(\mathrm{S}_{1}-\mathrm{S}_{6}\right)$ and representing the load with $\mathrm{L}$ (inductance), R (resistance), and e (back e.m.f). The phase voltages $\mathrm{VaN}, \mathrm{VbN}$, and $\mathrm{VcN}$ are the inverter output voltages.

The real time model current in vector form can be obtained from:

$$
v=R * i+L \frac{d i}{d t}+e m f
$$

Note that for recreation and exploratory outcomes, the inductive load back-emf is thought to be constant sinusoidal waveform. The discrete form of the predicted load current derived from equation (5) for $(\mathrm{k}+1)$ instant is: 


$$
i^{\text {predicted }}(k+1)=\left(1-\frac{R * T_{S}}{L}\right) i(k)+\frac{T_{s}}{L}(v(k)-\widehat{e . m . f}(k))
$$

The evaluated motor back e.m.f $\widehat{e . m .} f(k)$ can be found from the previous instant of time as:

$$
\widehat{e . m .} f(k-1)=v(k-1)-\frac{L}{T_{s}} i(k)-\left(R-\frac{L}{T_{s}}\right) i(k-1)
$$

Where, $\mathrm{T}_{\mathrm{s}}$ is the sampling time, and $\mathrm{v}(\mathrm{k})$ represents the voltage vector at time $(\mathrm{k})$ which has seven values for this type of inverter. Each value is tested to calculate the predicted current at time $(\mathrm{k}+1)$. The voltage vector that produce least cost function (less error); will be selected as a switching command to inverter switches.

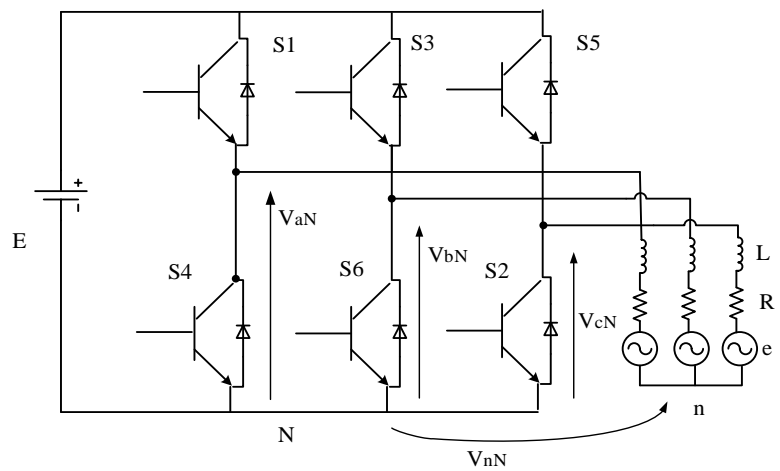

Figure 1. Topology of the DC battery source inverter.

\section{ASSESSMENT MODEL PRECISION AND RESULTS}

The simulation process for the inverter model is carried out using Matlab/Simulink. Finite (MPC) current control algorithm is applied to tracing the phase current references. The model parameters used are $\left(\mathrm{R}=10 \Omega, \mathrm{L}=10 \mathrm{mH}\right.$, e.m.f $=100 \mathrm{~V}$, and $\mathrm{T}_{\mathrm{s}}=25 \mu \mathrm{sec}$.). For (AE) approach, figures (2) demonstrate the error between the reference current command and its relative actual one, while figure (3) shows the actual $\varnothing$-a tracking its reference. Figures ( $4 \& 5$ ) exhibits the harmonics content for a selected window from the measured current and its distortion ratio for (AE) approach.

Figures (6-9) presents the same for (SE) approach, these results show that the model in the two approaches have nearly the same behavior. The percentage error (PE) approach when applied shows a slightly less error but with larger total harmonic distortion (THD) compared with the previous two approaches. This can be noticed in Figures (10-13).

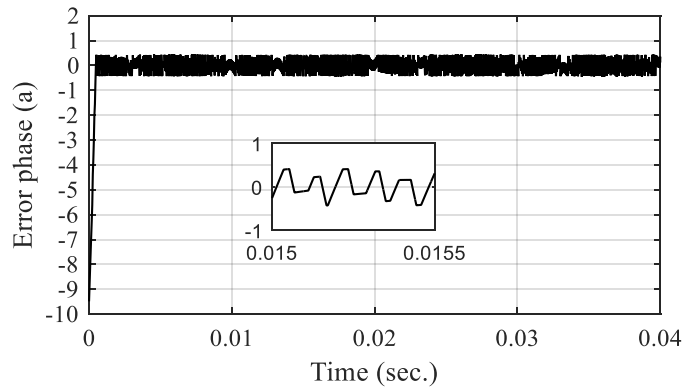

Figure 2. Error between the reference and actual current $\varnothing$ (a) (AE).

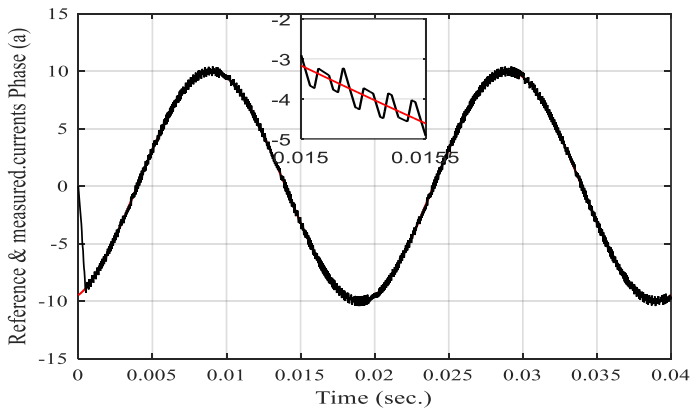

Figure 3. reference (red) and actual current $\varnothing$ (a) (AE) 


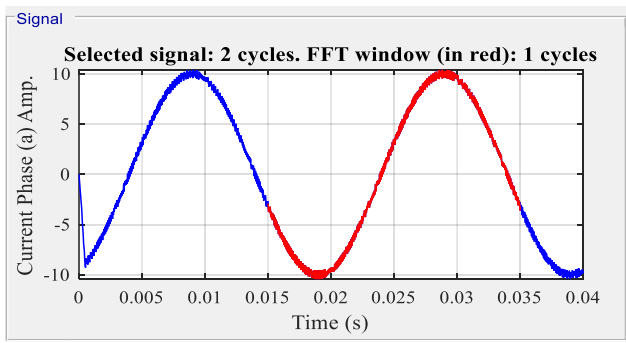

Figure 4. Selected current window for one cycle (AE).

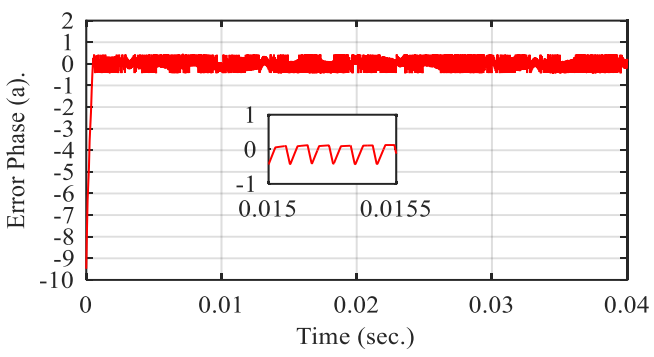

Figure 6. Error between the reference and actual current $\varnothing$ (a) (SE).

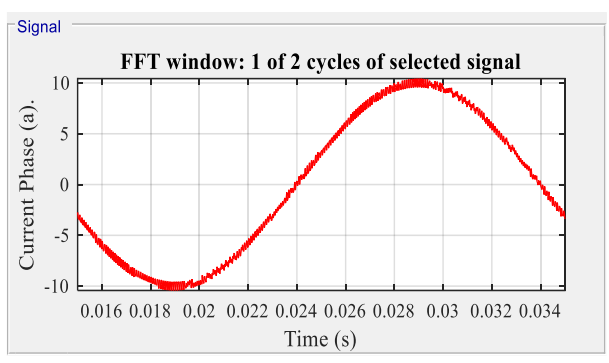

Figure 8. Selected current window for one cycle (SE)

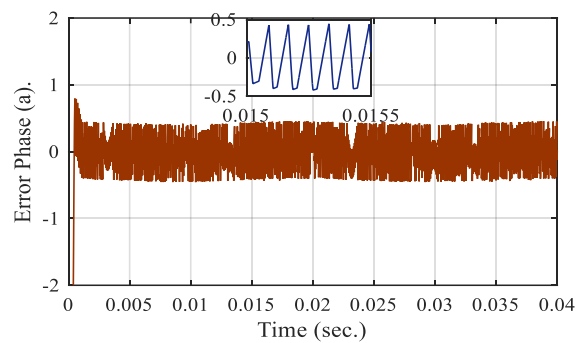

Figure 10. Error between the reference and actual current $\varnothing$ (a) (PE).

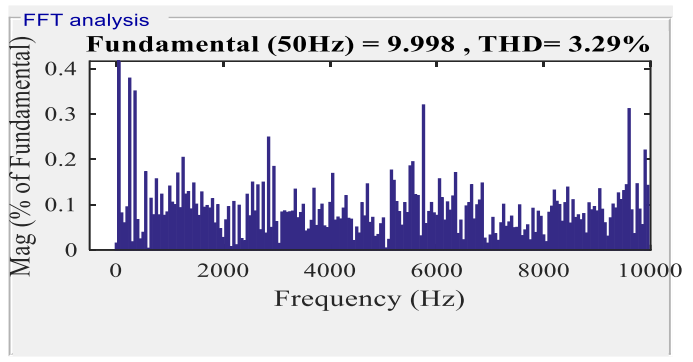

Figure 5. Harmonics content for the selected current

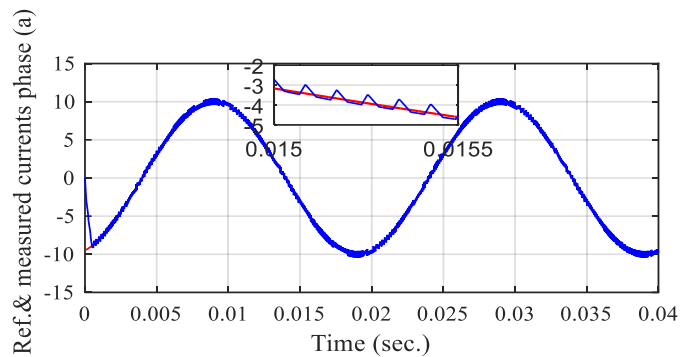

Figure 7. Reference (red) and actual current $\varnothing$ (a) (SE)

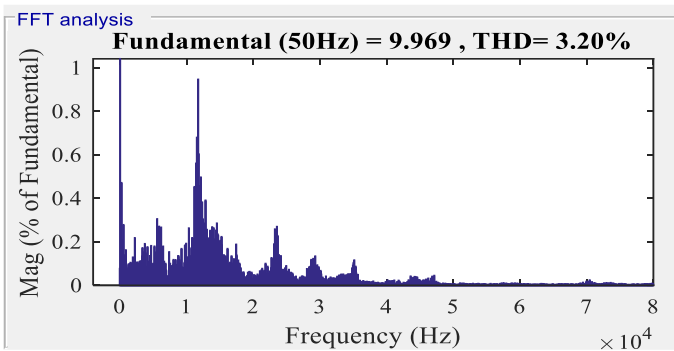

Figure 9. Harmonics content for the selected current

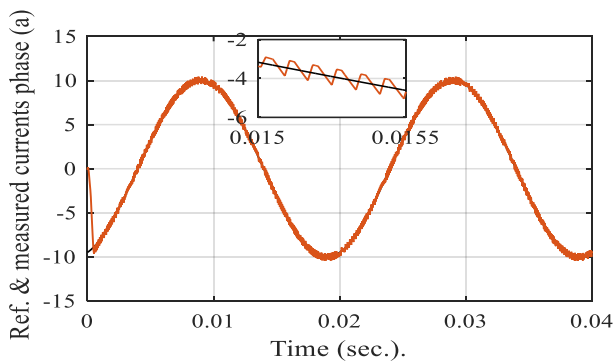

Figure 11. reference (red) and actual current $\varnothing$ (a) (PE) 


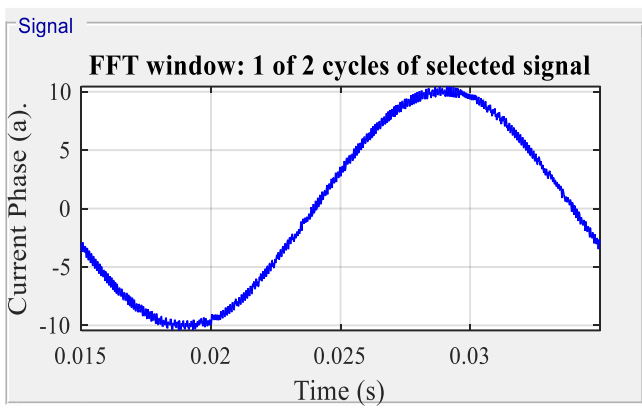

Figure 12. Selected current window for one cycle $(\mathrm{PE})$

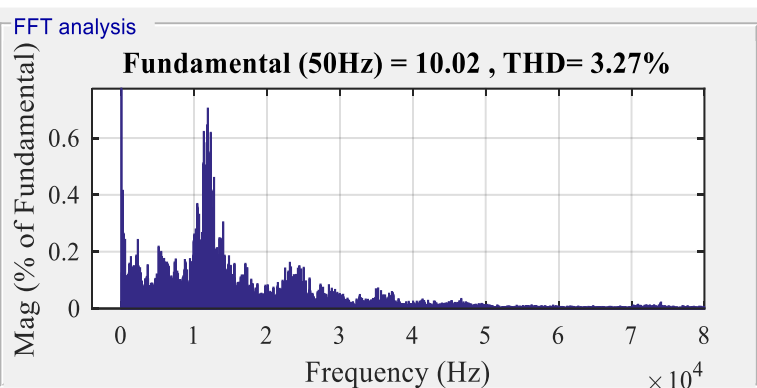

Figure 13. Harmonics content for the selected current

\section{CONCLUSION}

The aim of this work is to demonstrate and compare between various cost-function optimization approaches. The predictive control strategy (FCS-MPC) is used to drive inductive load via 3- $\varnothing$ battery source inverter. The analysis is carried out using Matlab/Simulink package, tha approaches under consideration are absolute, square, and percentage error, while the integral error is eliminated because of its need for long execution time. The obtained results show that for (AE) and (SE) there was rapprochement between them in error amplitude, output current harmonics content and executing time, but in case of (AE) a faster and mor sensitive for small error controller is needed. For the percentage error (PE) the error amplitude is slightly more than the previous two cases but there was a notable increase in harmonics content (THD). Since the deviations are squared, the SE gives a generally high weight to huge deviations. This implies the SE should be progressively valuable when enormous errors are especially unfortunate. One unmistakable favorable position of SE over AE is that SE keeps away from the utilization of taking the absolute for each error, which is unwanted in many numerical computing steps. The results approved the (FCS-MPC) performance quality, as can be seen in how the actual current tracks its reference command.

\section{ACKNOWLEDGEMENTS} this work.

The author might want to demonstrate thankfulness to Mustansiriah University for helping

\section{REFERENCES}

[1] B. Rahima, G Amar, B. Toufik, C. Mohamed, "High-performance active power filter implementation based on predictive current control," International Journal of Power Electronics and Drive System (IJPEDS), Vol. 10, No. 1, pp. 277-287 2019.

[2] N. Hong Quang, N. Quang, N. Hien, N. Binh, "Min Max Model Predictive Control for Polysolenoid Linear Motor," International Journal of Power Electronics and Drive System (IJPEDS), Vol. 9, No. 4, pp. 1666-1675 2018.

[3] Himabindu T., A.V.Ravi Teja, G. Bhuvaneswari, Bhim Singh, "Performance enhancement in a multilevel inverter fed PTC induction motor drive by optimal voltage vector selection," International Journal of Power Electronics and Drive System (IJPEDS), Vol. 10, No. 2, pp. 801-812 2019.

[4] Lim, Chee Shen, et al. "FCS-MPC-based current control of a five-phase induction motor and its comparison with PI-PWM control." IEEE Transactions on Industrial Electronics, Vol. 61, no. 1, pp. 149-163, 2014.

[5] Vargas, Rodríguez, Ammann, and Wheeler, "Predictive Current Control of an Induction Machine Fed by a Matrix Converter with Reactive Power Control". IEEE Transactions on Industrial Electronics, Vol. 55, No. 12, pp. 4362-4371, 2008.

[6] H. Abu-Rub, J. Guziñski, Z. Krzeminski, and H. A. Toliyat, "Predictive current control of voltage-source inverters," IEEE Trans. Ind. Electron, vol. 51, no. 3, pp. 585-593, Jun. 2004.

[7] Metri, J.I.; Vahedi, H.; Kanaan, H.Y.; Al-Haddad, K, "Real-Time Implementation of Model-Predictive Control on Seven-Level Packed U-Cell Inverter," IEEE Trans. Ind. Electron. Vol. 63, pp. 4180-4186, 2016.

[8] Kouro, S.; Perez, M.A.; Rodriguez, J.; Llor, A.M., "Model Predictive Control: MPC's Role in the Evolution of Power Electronics," IEEE Ind. Electron. Mag. Vol. 9, pp. 8-21, 2015.

[9] J. Rodriguez, and P. Cortes, "Predictive Control of Power Converters and Electrical Drives", a John Wiley \& Sons, Ltd. Publication, first edition, 2012.

[10] T. Geyer, "Low Complexity Model Predictive Control in Power Electronics and Power Systems", PhD. Thesis, Swiss Federal Institute of Technology, 2005. 
[11] LiupingWang, Shan Chai, Dae Yoo, Lu Gan and Ki Ng, "PID and Predictive Control of Electrical Drives and Power Converters Using MATLAB/SIMULINK, 2015 John Wiley \& Sons Singapore Pte. Ltd.

[12] Bose, Bimal K," Modern power electronics and AC drives" Prentice Hall PTR, 2002.

[13] Sungil Kima, Heeyoung Kimb," A new metric of absolute percentage error for intermittent demand forecasts", International Journal of Forecasting, Vol. 32, pp. 669-679, 2016.

[14] Cort J. Willmott, Kenji Matsuura, "Advantages of the mean absolute error (MAE) over the root mean square error (RMSE) in assessing average model performance", CLIMATE RESEARCH, Vol. 30, pp. 79-82, 2005.

[15] Seyed Hesam Asgari, Mohammad Jannati, Tole Sutikno, Nik Rumzi Nik Idris, "Vector Control of Three-Phase Induction Motor with TwoStator Phases Open-Circui," International Journal of Power Electronics and Drive System (IJPEDS), Vol. 6, No. 2, pp. 282-292, 2015.

[16] Hasabelrasul, Hashim \& Yan, Xiangwu. "Comparison of Multicarrier PWM Techniques for Cascaded H-Bridge Multilevel Inverter." International Journal of Power Electronics and Drive Systems (IJPEDS), Vol, 8, No. 2, pp. 861-868, 2017.

[17] R. Gunabalan, V. Subbiah, "Speed Sensorless Vector Control of Induction Motor Drive with PI and Fuzzy Controller," International Journal of Power Electronics and Drive System (IJPEDS) Vol. 5, No. 3, pp. 315-325, 2015.

[18] Yasir M.Y. Ameen, Bashar A. Fadheel, Ali J. Mahdi, "Third harmonic injection PWM technique for maximizing DC-BUS utilization of Five-Phase VSIs", Indonesian Journal of Electrical Engineering and Computer Science, Vol. 17, No. 3, March 2020, pp. 1607 1617.

[19] Siami, Mohsen, et al., "A Computationally Efficient Lookup Table Based FCS-MPC for PMSM Drives Fed by Matrix Converters," IEEE Transactions on Industrial Electronics.Vol. pp, 1-1, 2017.

[20] M. Reyasudin Basir Khan, Jagadeesh Pasupuleti, Jabbar Al-Fattah, Mehrdad Tahmasebi, "Energy management system for PV-Battery microgrid based on model predictive control", Indonesian Journal of Electrical Engineering and Computer Science, Vol. 15, No. 1, pp. 20 25, 2019.

[21] P Chenchu Saibabu, Hitesh Sai, Saksham Yadav, C. R Srinivasan, "Synthesis of model predictive controller for an identified model of MIMO process," Indonesian Journal of Electrical Engineering and Computer Science, Vol. 17, No. 2, pp. 941 949, February 2020.

[22] Omar, Riyadh G., and Rabee'H. Thejel. "Finite Control Set Model Predictive Current Control FCS-MPC Based on Cost Function Optimization, with Current Limit Constraints for Four-Leg VSI," Iraqi Journal for Electrical \& Electronic Engineering Vol.12. No.1. 2016.

[23] H. Young, M. Perez, and Jose Rodriguez "Analysis of Finite-Control-Set Model Predictive Current Control with Model Parameter Mismatch in a Three-Phase Inverter" IEEE Transactions on Industrial Electronics, Vol.63, No. 5, May 2016.

[24] C. Garcia, J. Rodriguez, C. Silva, C. Rojas, P. Zanchetta, and H. Abu-Rub, "Full Predictive Cascaded Speed and Current Control of an Induction Machine", IEEE Transactions on Energy Conversion, Vol. 31, Issue: 3, Sept. 2016.

[25] Riyadh G. Omar, "FCS-MPC strategy for a five-phase voltage source inverter using maximum load current constraint”. IEEE, 2018 1st International Scientific Conference of Engineering Sciences - 3rd Scientific Conference of Engineering Science (ISCES), Iraq, 2018.

\section{BIOGRAPHIES OF AUTHORS}

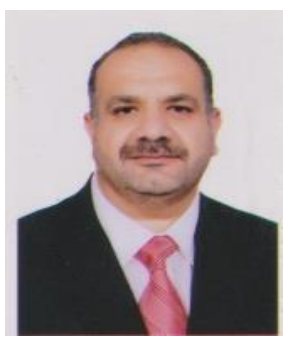

Dr. Riyadh G. Omar is a lecturer in the Electrical Engineering department, Mustansiriyah University, Baghdad-Iraq, for 18 years in power system analysis \& power electronics. He is a member in the electrical engineering Department council. He has many publications mainly in power electronics and predictive control. 